\title{
Historiens slut - Tio år efteråt
}

\section{Av Roddy Nilsson, fil.dr i historia}

\author{
Länk till presentation av Roddy Nilsson
}

1989 publicerade den amerikanske diplomaten och filosofen Francis Fukuyama en artikel i den amerikanska tidsskriften The National Interest[1] med rubriken "The End of History", vilken 1992 följdes upp av ett betydligt mera omfattande och filosofiskt inriktat arbete betitlat The End of History and the Last Man[2] där han - framför allt med stöd i Hegels filosofiska system - utvecklade tesen om den liberala demokratins seger och hegemoni.[3] Boken utkom samma år även på en rad andra språk, däribland svenska.[4] Fukuyamas teser utlöste en ström av recensioner, kommentarer och artiklar.[5]

Budskapet var vid en första anblick enkelt och slagkraftigt: genom den kommunistiska praktikens fall hade den liberala demokratin och marknadsekonomin slutgiltigt visat sig överlägsen alla andra typer av social organisation. Denna samhällsordning sågs som slutmålet för den förnuftiga och i viss mån nödvändiga utvecklingen mot mänsklighetens slutmål. När det inte längre fanns någon rivaliserande - verklig eller tänkt - samhällsmodell med universalistiska anspråk som kunde utmana den liberala modellen hade således också Historien med stort $\mathrm{H}$ fullbordats och nått sitt slut.

Arbetet kan betraktas som ett uttryck för - och ett försök att skapa en politisk-ideologisk legitimering av - västs seger över en kollapsande kommunistisk praktik. Denna tes framfördes vid denna tid i delvis olika former av ett flertal representanter och institutioner, inklusive presidenten George Bush, för det amerikanska utrikespolitiska etablissemanget och kom därigenom att framstå som den officiella uppfattningen. Fukuyama gav ett svar på innebörden i det nya tillstånd världen befann sig i. Vad som hade hänt var inte, menade Fukuyama, bara ytterligare en skiftning i de hegemoni- och maktförhållanden som världshistorien varit fylld av. Den liberala demokratin hade segrat inte bara därför att den visat sig vara ekonomiskt, politiskt och militärt starkare än kommunismen utan också, och framför allt, därför att den visat sig vara moraliskt överlägsen. Fukuyama gav därmed i historiefilosofisk form ett svar inte bara på frågan vad det kalla kriget verkligen handlat om utan också om hela världshistoriens mål.

Det historieteoretiskt verkligt intressanta med arbetet framkommer emellertid om man frigör sig från de omedelbart politiska övertoner som finns i frågan. Jag ska ta upp och diskutera några aspekter på Fukuyamas arbete, framför allt kring hur kritik från olika utgångspunkter kan riktas mot den typ av tänkande det representerar. En fråga som också bör ställas är om "Historiens slut" verkligen är ett attraktivt tillstånd. Vad som i förstone av många uppfattades som en bekräftelse på att världen trots allt gick mot ett lyckligare och bättre tillstånd kan då i stället få en helt annan innebörd. Många av dem som såg vad som sades i Historiens slut och den sista människan som en bekräftelse på Västvärldens politisk-ideologiska seger missade nämligen att det är högst tveksamt - vilket Fukuyama själv också erkänner - om "den sista människan" också är en lycklig människa.

\section{Ett gammalt projekt}

På sätt och vis anknöt Fukuyama till ett klassiskt historiefilosofiskt projekt.[6] Historien får sin mening och förståelse utifrån en uppfattning om vilka händelser och fenomen som är de centrala och viktiga och därmed konstituerande för dess mål. Det handlade om att i likhet med Kant, Hegel, Marx, Comte, Spengler och Toynbee med flera försöka finna ett 
meningsfullt mönster i det historiska skeendet och att därmed avslöja och förklara de mekanismer och processer som kan tänkas ligga bakom detsamma. För Hegel låg meningen i historien i förverkligandet av friheten. Historien var dock inte liktydigt med människans historia i sin helhet. Likaväl som historien hade ett slut hade den också en början. För att "inträda" i historien måste samhällen uppnå en viss grad av organisation och utveckling i politisk, juridisk, ekonomisk, kulturell mening. Folken i Afrika och Asien saknade därför, enligt Hegel, nästan alla historia i verklig mening.

För Spengler och Toynbee var historien en berättelse om kulturers uppgång och fall vilkas utveckling skildrades i en biologisk metaforik.[7] Orsakerna till att kulturer "vissnade" bort och gick under var den lagbundna process av kulturell degeneration och minskande livskraft som utmärkte cykelns deklinationsfas. Denna historiesyn formulerades under intryck av de pessimistiska undergångsstämningar som utgjorde ett väsentligt inslag i mellankrigstidens kulturliv och som oftast bottnade i en konservativ kritik och oförståelse av moderniteten. Historiesynen som sådan vände sig framför allt mot en konventionellt linjär syn på historien av typen "the whig interpretation of history" med dess betoning på historien som en ständig progressiv rörelse mot allt större fulländning.[8] Särskilt hos Spengler fanns också en utpräglat relativistisk syn på historien där varje kulturs storhet och egenvärde framhölls liksom det omöjliga i att jämföra olika kulturer. Framhållandet av denna kulturella inkommensurabilitet var främst en kritik mot den västerländska etnocentrismen och dess anspråk på att vår kultur skulle utgöra måttstock för alla andra folk. Den pessimistiskt och idealistiskt färgade konservatism som Spengler och Toynbee respresenterade har spelat en inte obetydligt roll för formandet av den borgerliga västerländska världsbilden.

Fukuyamas tankar kan också ses som ett återuppväckande av tesen om "ideologiernas död" som redan under 1950-talet framfördes av Daniel Bell.[9] Denne tolkade utvecklingen i de västliga avancerade demokratierna som att de ideologiska konflikterna var på väg att försvinna i takt med omvandlingen mot det postindustriella samhället. Genom den ideologiska samstämmighet - eller snarare avideologisering - som härigenom uppnåddes i det postindustriella samhället kom de motsättningar och konflikter som fanns inte längre att röra hur detta samhälle skulle se ut utan hur det så rationellt och effektivt som möjligt skulle styras. Denna diskussion känns också igen från den svenska arenan där Herbert Tingsten vid mitten av 1960-talet drev en likartad tes.[10] Liknande tankar i marxistisk tappning kan återfinnas i Herbert Marcuses One-Dimensional Man.[11] Marcuse menade att det stigande välståndet hade lett till allt mera nöjda och passiviserade människor. Historiens motor - klasskampen - var på väg att tappa fart.

Den liberala demokratins seger och "Historiens slut" i Fukuyamas tappning skall naturligtvis inte tolkas som att alla stater bekänner sig till liberal demokrati och marknadsekonomi eller att alla konflikter mellan och inom nationer kommer att försvinna. Utifrån den hegelianska tolkningen av världshistorien som Fukuyama anammar är dessa konflikter mera att betrakta som krusningar på den stora historiens yta eller på sin höjd som tillfälliga bakslag utan djupare betydelse för den lagbundna och oemotståndliga utvecklingen mot slutmålet.

Konstaterandet av det i och för sig starka kausala sambandet mellan liberal demokrati och marknadsekonomi och denna kombinations oöverträffade effektivitet i välstånd och trygghet räcker inte för att slutgiltigt utnämna denna samhällsordning till historiens slutmål. För detta måste betydligt starkare skäl anföras. Även om den kommunistiska praktiken gjort bankrutt är detta i sig inget stöd för Fukuyamas anspråk på att den liberala demokratin innebär historiens slutstadium.

Detta stöd finner han i förbindelsen mellan den liberala demokratin och Hegels filosofiska antropologi. Vad som verkligen ger den liberala demokratin dess livskraft och styrka är dess förmåga att bättre än någon annan social organisationsform tillfredsställa människans, enligt Hegel och Fukuyama, mest utmärkande egenskap, nämligen längtan efter att bli sedd och respekterad av andra och därmed i sista hand att bli erkänd som människa. Människans 
härmed sammanhängande förmåga till fria moraliska val finner Fukuyama då inte bara som den grundläggande skillnaden mellan människa och djur utan också som den mekanism varigenom människan kan uppnå och förtjäna denna respekt. Fukuyamas historieteori inskränker sig därmed inte till att vara en teori om samhället utan ger också ett svar på vad det innebär att vara människa.

Vad som hos Fukuyama avses med historien blir förståeligt endast om man är medveten om den innebörd begreppet har i det hegelianska systemet. Liksom i alla historiefilosofiska system får skeendet sin mening och förståelse utifrån en uppfattning om vilka händelser och fenomen som är centrala eller viktiga och därmed konstituerande för historien fattad som en helhet. För Hegel är den verkliga historien en berättelse om hur ideologierna (idéerna) verkar som rationella och ordnande principer i en rörelse mot allt mera fulländade sociala och politiska organisationsformer. I hegelianskt språkbruk uttrycks detta som Andens gradvisa uppstigande till allt högre medvetande om sig själv. Historiens drivkrafter är idéerna uttryckta som en logisk och dialektisk process vilken i sig innehåller en utveckling mot det absoluta. Denna idé begränsar dock inte sina uttryck till det individuella mänskliga medvetandet utan förkroppsligas också slutligen i ett samhälles sociala och politiska institutioner. Historien manifesterar sig i världshistorien sedd som en sammanhängande process som tar sin början i Orienten och når sitt slut i Västvärlden. "Historiens slut" är för Hegel, liksom för hans efterföljare Fukuyama, en händelse som i sista hand sker i idéernas värld. Denna är i sin tur bara fattbar för filosofin, tänkandets mest utvecklade form.[12]

Som nämnts utsattes Fukuyamas teser från flera håll för skarp kritik. Det har framhållits naturligtvis framför allt av författaren själv - att mycket av denna orsakades av att kritikerna missuppfattade eller inte förstod vad som egentligen sades i de båda skrifterna.[13] Även om en stor del av kritiken utformades som empiriska eller teoretiska argument mot vad som framfördes bör man nog förstå en stor del av invändningarna som en kritik av Fukuyamas hegelianskt influerade historiefilosofi som sådan. Denna kritik har en lång tradition i förra århundradets positivistiska filosofi och dess avståndstagande från vad som betraktades som metafysiska spekulationer utan förankring i en konkret och iakttagbar verklighet. Denna kritik bör skiljas från den som riktar sig mot det sätt på vilket Fukuyama använt Hegels filosofi i sig. Utgångspunkten här är den rysk-franske filosofen Alexandre Kojèves utläggningar kring Hegels filosofi vilka utgavs under 1930-talet. Kritiker menade att Fukuyamas tolkning av Hegel innehöll flera problematiska inslag. Särskild kritik har - inte direkt överraskande - riktats mot försöket att göra Hegel till en förespråkare för vad vi benämner liberal demokrati. Delvis sammanhängande med detta problem är också huruvida det hegelianska frihetsbegreppet är möjligt att inordna i en liberal tradition.

\section{"Historiens slut" eller det "postmoderna tillståndet"?}

På ett sätt hade naturligtvis Fukuyama fel. Historien tog inte slut vare sig 1989 eller 1992.[14] Historien är något som pågår hela tiden och kommer så att göra så länge människan finns kvar. Det är tydligt att Fukuyama måste mena något annat och att svaret på frågan om han fått rätt eller fel inte är särskilt enkelt att ge. Vad som gör Historiens slut och den sista människan verkligt intressant och stimulerande är dess blandning av filosofisk spekulation och empiriskt grundad samhällsteori. Samtidigt utgör detta dess specifika svårighet. För även om Fukuyama försöker underbygga sin tes med hjälp av samhällsteori och empiriskt stöd vilar denna framför allt på filosofisk spekulation som $a$ priori knappast låter sig vederläggas av vad som sker i den värld vi förnimmer med våra sinnen. Den blir med andra ord omöjlig att i poppersk mening falsifiera i synnerhet som dess prognoser för den framtida utvecklingen inte innehåller några tidsangivelser.

Fukuyama menar att utvecklingen endast kan gå i en riktning, nämligen att allt fler stater uppnår - eller strävar efter att uppnå - detta stadium av "Historiens slut". Fler och fler länder övergår till att bli liberala demokratier och marknadsekonomier. Några alternativ till 
denna samhällsordning finns inte längre efter sovjetkommunismens sammanbrott. Fukuyama ser alltså snarare "Historiens slut" och den liberala demokratins seger som, åtminstone än så länge, mera en tendens än som ett absolut tillstånd. Skulle Fukuyamas iakttagelser visa sig vara felaktiga idag eller om tio eller femtio år kan alltid hans tes försvaras med att vi ännu inte nått dit men att vi likväl kommer att göra det i framtiden.

Politiskt kan Fukuyamas teser ses som försök att ideologiskt legitimera USA:s globala dominans. Historiografiskt kan Fukuyama ses som en i den långa raden av profeter, filosofer, författare och andra som förkunnat någon form av historiens slut. Här nedan ska jag kort diskutera något kring den teoretiska och filosofiska kritiken av Fukuyama. Detta måste dock göras med vissa modifikationer. Jag anser då att frågan om en tes av detta slag är riktig eller oriktig (än mindre om sann eller falsk i kunskapsteoretisk mening) är fel ställd och inte låter sig avgöras. Däremot kan man, och bör man, diskutera såväl de moraliska som politiska konsekvenserna som den vetenskapliga fruktbarheten i sådana teser. Detta innebär naturligtvis också att underliggande faktapåståenden, verklighetsbeskrivningar, begrepp, generaliseringar etc i sig bör utsättas för granskning.

Om den politiska kontexten för Fukuyama var östblockets sammanbrott är det värt att också påminna sig den kulturella i bredare mening. Drygt tio år före publiceringen av Historiens slut hade den franske filosofen Jean-François Lyotard formulerat vad som senare kom att framstå som det postmoderna credot i det han deklarerade alla metaberättelsers död.[15] Under senare delen av 1980-talet och första delen av 1990-talet svepte den postmoderna vågen på allvar in över (Västvärldens) akademiska institutioner och kultursidor.[16] Postmodernisterna förnekar möjligheten att göra precis vad Fukuyama försöker göra, nämligen att, oberoende av tid och rum, utge sig för att kunna överblicka världen. Fukuyamas hävdande att kunna se mönstret för "Historiens slut" blir från postmodern synvinkel ett totalitärt sätt att tänka genom att det är allomfattande och inklusivt till sin karaktär. Det totalitära draget visar sig också i anspråket på att både kunna förklara vad som skett och vad som kommer att ske. Den postmoderna kritiken mot Fukuyama riktar sig även mot dess hegelianska grundvalar i det att Hegel filosofiskt, med allt vad detta innebär, såg moderniteten som ett kvalitativt nytt stadium. På samma gång är Fukuyamas (och Hegels) tes naturligtvis ett hot mot hela den postmoderna uppfattningen då ett "Historiens slut" skulle innebära att postmoderniteten aldrig inträtt eller kommer att inträda.

Förespråkandet av ett postmodernt orienterat synsätt kan vid första anblicken framstå som raka motsatsen till Fukuyamas tes. Postmodernismens intåg kan emellertid också tolkas som en annan form av historiens slut. Även om historien inte slutade i en stor berättelse om liberalismens och marknadsekonomins seger slutade den i en oändlig mångfald av små och lokala berättelser. De postmoderna små berättelserna är inkommensurabla, ständigt föränderliga och oavslutade.

Kritiker av postmodernismens tes om alla metaberättelsers död har pekat på att också detta i sig kan ses som en metaberättelse och att tesen därför skulle vara en självmotsägelse. Detta är dock en enligt mitt sätt att se en feltolkning. Detta kan illustreras med det mycket omdiskuterade relativismargumentet. Den mycket vanliga kritik som hävdar att påståendet "allt är relativt" är en självmotsägelse missar poängen. Att allt är relativt kan tolkas som att inget (i kunskapsrealistisk mening) är sant, alltså kan inte heller påståendet att "allt är relativt" ha ett absolut sanningsvärde.[17] Ett ännu radikalare avfärdande av kritiken skulle kunna utgå ifrån att tvistefrågan (i filosofisk mening) är meningslös utanför ett modernistiskt tänkande. En mera pragmatisk hållning skulle i stället erkänna att det kan finnas utsagor med absolut sanningsvärde men att vi antingen (i) inte kan veta (ii) att de är av den karaktären att de närmast är att likna vid plattityder eller elementära matematiska sanningar som inte spelar någon som helst roll för vem man är eller det liv man vill leva.

I den mån avfärdandet av alla metaberättelser också är en metaberättelse är den det av ett annat slag. Att leva i det postmoderna är inte att leva i en epok där man vet alla svar inklusive svaret på den stora frågan vad allt handlade om - utan att leva i ett öppet och 
osäkert tillstånd utan klar färdriktning. Den postmoderna kritiken bör betraktas som en hypotes som bör bedömas utifrån sin användbarhet. Den grundar sig inte heller på en kunskapsrealistisk uppfattning om världen som den verkligen är. Den innehåller inga påståenden om att världen i sista hand är vare sig av materiell eller andlig natur. Historien innehåller inte någon mening eller något slut som någon självutnämnd uttolkare, vare sig han heter Hegel, Marx, Hitler eller Fukuyama, kan avslöja. Att hävda att historien inte har någon inneboende mening innebär dock inte att vi inte kan ge den mening. Det är vad vi människor hela tiden gör på olika plan; i form av livshistorier och små eller stora projekt. Men det är vi människor som gör det.

Det finns, som Keith Jenkins skriver, bara två möjligheter. Antingen är historien så att säga "up for grabs" eller så är den något vi kan glömma.[18] Den postmoderna kritiken mot historieskrivningen gäller både innehåll och form. Hayden White har i en rad lång skrifter visat hur historieskrivningens karaktär är starkt formad av olika kanon för narrativa strukturer. Kärnan i Whites kritik är att vilken historia som framställs inte avgörs av hur det förflutna gestaltade sig utan av valet av narrativ genre. Historieskrivningen är relativ i den bemärkelsen att den som produkt är en funktion av hur historikern använder språket. Av detta följer också att historieskrivningen närmar sig fiktionen. Det är dock viktigt att det alltjämt finns skillnader mellan historieskrivning och litteratur. Skillnaderna består dock inte i att historieskrivningen beskriver verkligheten medan litteraturen är fiktiv utan i de båda framställningsformerna vanligen arbetar utifrån olika sätt att strukturera sina berättelser.[19]

\section{Popper, Berlin och Nietzsche}

Men det finns också en rivaliserande tankelinje till Fukuyama inom det liberala lägret. Hos liberala filosofer som Popper och Berlin finns en annan, om man så vill, mindre totalitär eller sluten tolkning av vad liberalismen står för. Skillnaderna är alltså framför allt historieteoretiska. Det kan också hävdas att Popper och Berlin i själva verket bidragit starkt till att den typ av historiefilosofi - av Popper benämnd "historicism" - som Fukuyamas arbete är ett utslag av under lång tid befunnit sig utanför huvudfåran i de akademiska diskussionerna. För Popper är de förutsägelser historicismen innehåller profetior som inte har med vetenskap att göra. Den obönhörliga utveckling historicisterna ser i historien bygger på en falsk analogi med den biologiska evolutionsläran som bara blir ännu mindre relevant genom sammankopplingen med ett teleologiskt synsätt. Popper menar att följden av denna typ av historiefilosofi blir att man tar ifrån människorna värdigheten av att vara människa genom att hävda att historien handlar om något större än de själva. Popper har dock också beröringspunkter med Fukuyama. Förutom liberalismen fanns hos Popper, liksom hos Fukuyama, en mycket positiv syn på naturvetenskapen och dess metoder. Poppers scientism är en viktig förutsättning för hans kritik av historicismen i det att dess spekulativa och metafysiska form inte ansågs svara upp emot de metodologiska krav som man menade borde vara en utgångspunkt för den vetenskapliga verksamheten. En mindre scientistisk men inte desto mindre stark kritik mot den typ av tänkande som Fukuyama står för återfinns hos en annan central liberal företrädare, idéhistorikern och filosofen Isaiah Berlin.[20] Centralt för både Popper och Berlin är hur de vänder sig emot tanken på en enda allomfattande lösning på historiens problem. Berlin betonar skillnaden mellan pluralism och liberalism och att det mycket väl finns liberala teorier som inte är pluralistiska.[21] Pluralismen i Berlins tolkning påminner starkt om den syn som idag finns hos många postmodernister. Berlin betonar att inga färdiga svar finns på frågor som har med värde och moral att göra. Ännu viktigare är erkännandet av att det finns vissa frågor där de olika svar som ges inte är möjliga att förena och att det måste finnas utrymme för att kunna hysa dessa olika uppfattningar. Medan Popper och i synnerhet Berlin kan betraktas som pluralister kan Fukuyama i denna mening ses som en icke-pluralistisk liberal.

Som nämnts finns vissa inslag i Fukuyamas tänkande som kan tolkas som att författaren själv känner tveksamhet om det "Historiens slut" han ser verkligen är ett möjligt och eftersträvansvärt tillstånd. Det är oklart om det är en fråga om tvivel om hur detta tillstånd 
kommer att gestalta sig eller om det rentav är en fråga om tveksamhet inför hela det historiefilosofiska projektet. Det ena kritiska spår Fukuyama själv tar upp är det som pekar mot att den liberala demokratin inte kan leva upp till att tillfredsställa människornas behov av erkännande därför att liberalismen som samhällsordning värderar människor olika - en uteliggare och en framgångsrik företagare vinner inte samma erkännande.[22] Denna kritik tar så att säga sin utgångspunkt i att det är fel på liberalismen. Det andra kritiska spåret tar i stället sin utgångspunkt i att bristerna finns i den filosofiska antropologin. Människan är till sin natur inte sådan att hon låter sig nöja med att bli erkänd som en människa i sig. Hon strävar efter att bli erkänd som något mera eller något större än andra människor.[23] Människan vill göra stordåd och bli världsberömd som fältherre, konstnär, forskare, filmstjärna etc eller bara som den som är bäst på något i grannskapet eller hembyn. Denna drivkraft till att erkännas som förmer än andra innehåller alltid ett moment där detta kommer i konflikt med andras strävan efter detsamma. För som Fukuyama själv skriver: "[...] while as a society we are in some way dedicated to the principle of equal recognition, our lives are in fact filled with a continuing struggle for unequal recognition. Most of us do not want to be recognized merely as the equals of our fellows, we want to be better."[24] Denna kritik utgår filosofiskt framför allt från Nietzsche och uppfattningen om att den moderna civilisationen var på väg att skapa tillfredsställda och nöjda människor. Nietzsche menade att kampen, att ha något att slåss för, var det som framkallade det liv som var värt att leva. Om människorna skulle vara överens om alla väsentliga frågor skulle därmed också livet övergå till en vegeterande tillvaro som mest liknade hundens.[25]

\section{Rortys pragmatiska kritik}

Vid ingången till ett nytt millennium kan vi konstatera att både debatten om "Historiens slut" och postmodernismen stannat av. Samtidigt är det knappast så att vad som skett under de senaste åren i före detta Jugoslavien, Mellersta östern, Rwanda och i det forna Sovjetimperiet övertygat särskilt många om att historien håller på att ta slut. För att inte tala om den internationella skuldkrisen och att 1 miljard av jordens befolkning lever under fattigdomsgränsen, de ökande etniska konflikterna inom en rad stater, de växande problemen inom miljöområdet och ekologin, ökande ekonomiska och sociala klyftor, den återuppväckta högerextremismen etc. Ändå skulle det gå att tolka vad som skett som att Fukuyama faktiskt på ett sätt hade rätt. Det liberala systemet är förvisso idag utsatt för växande kritik men denna kritik sker till största delen inom systemet. Det handlar mera om, i synnerhet för ledande politiker och marknadsaktörer i Väst, om hur man ska förvalta och på sin höjd justera inom systemet än att presentera alternativa lösningar på problemen.

Betydligt mera talar dock för att vår värld befinner sig i postmoderniteten än i slutet på historien. Även om liberalismen ännu framstår som den enda utopin[26] har euforin svalnat betänkligt och det finns idag en växande skepsis mot både marknad och demokrati eller i varje fall deras sätt att fungera. Det finns också en ökande misstro mot demokratin som beslutsform inte minst beroende på att stora grupper upplever att deras reella möjligheter att styra och påverka samhällsutvecklingen minskat på bekostnad av den globala kapitalismen. Inte mycket tyder på världen är på väg in det tillstånd av harmonisk inomliberal konkurrens som de mest hängivna anhängarna av Fukuyamas tes trodde på.

Vad som dessutom gör talet om "Historiens slut" till en både farlig och arrogant tes är dess teleologiska utformning vilken underordnar nuet en mer eller mindre avlägsen framtid. Miljoner människor runt om på vår jord lider dagligen av krig, svält och sjukdom samtidigt som den nya världsordningens försvarare - antingen det är västmakterna, världsbanken, internationella valutafonden eller de transnationella företagen - i sin självgodhet kan säga att de inte bara har makten utan också historien på sin sida. Även om företrädarna sällan uttrycker sig i historiefilosofiska termer - men ofta inte mindre metafysiskt - finns klara likheter. När t ex marknadens egenskaper och funktion beskrivs som en osynlig hand eller som något som ställer krav eller reagerar är detta återklanger av tidigare århundradens filosofiska språkbruk. 
Vidare frågor kan ställas: måste människorna acceptera att vägen till det tillstånd Fukuyama kallar "Historiens slut" går via blodiga offer och lidande? Vilken tröst har de som är offer i denna process av att de av amerikanska filosofer får sig omtalat att de är på väg in i historiens slut? Att det inte finns någon annan väg? Fukuyamas tes innebär - om vi accepterar den - att all kritik i djupare mening mot världsordningen faktiskt omöjliggörs. Historieskrivningen riskerar att antingen handla om trivialiteter eller att återfalla till tidigare epokers evolutionära och legitimerande funktion.[27] Vad ska man säga om alla de människor och kulturer som aldrig hört talas om Fukuyama, Hegel eller "Historiens slut"? Är de omedvetna delar i vad Hegel kallade världsanden och Fukuyama den liberala demokratin? Tesen om "Historiens slut" är raka motsatsen till uppfattningen att historien är en öppen och oförutsägbar process. Den omyndigförklarar i djupare mening människorna då det inte är vi som styr och formar historien utan krafter vi i grunden inte kan påverka.

Sedd på detta sätt blir den postmoderna kritiken mot de stora berättelserna och de totalitära konsekvenser dessa har inbyggda i sig ännu mera begriplig. När denna kritik formulerades riktade sig denna framför allt mot en urartad och förtryckande kommunistisk praktik och de katastrofala resultat denna fört med sig. Att Sovjetblocket fallit och att den stora berättelsen i denna form är djupt diskrediterad gör emellertid inte denna kritik mindre relevant idag. Om det nu är så att det idag bara återstår en stor berättelse - den om den liberala världsordningen som "Historiens slut" - innebär detta inte att vi måste acceptera vare sig denna berättelse i sig eller de stora berättelserna över huvud taget.

Forskare och debattörer världen över pekar idag allt mera på hur den liberala demokratin håller på att förändras inifrån. Det paradoxala blir då att när det främsta yttre hotet i form av sovjetkommunismen försvunnit kan diskussionen kring den liberala demokratin på ett nytt, mera livaktigt och förutsättningslöst sätt riktas mot dess inre; inte bara mot dess tillväxtskapande mekanismer utan också mot dess tendenser att skapa allt större klyftor; inte bara mot dess formella demokratiska beslutsprocesser utan också mot det faktum att allt flera människor upplever sig ha allt mindre reellt inflytande. Denna nya inre kritik, antingen den uttrycks som postmodern identitets- eller mikropolitik, utomparlamentariska proteströrelser, icke-kommunistisk vänsterpolitik, välfärdsstatlig socialreformism, kommunitärt inspirerad "local politics" eller något annat av de många tänkbara alternativ som finns eller kan uppstå är en utgångspunkt för att se historien som en fortgående process. Om vi - vilket jag menar vi bör göra - accepterar att vår värld har förändrats i den riktning förespråkarna för en postmodernismen eller pragmatismen menar innebär detta att vi mindre bör uppehålla oss vid den ofruktbara diskussionen om vad världen som metaberättelse ska kallas för att i stället mera ägna oss åt att försöka se till att den blir bättre som den faktiskt är. Det handlar om ett avvisande av alla former av historisk lagbundenhet och om en betoning på kontingensen, det obestämda, icke-nödvändiga, det som ger historien dess öppna karaktär. Det handlar inte om att försöka konstruera en ny metaberättelse som alternativ eller rival till vad som kallas den liberala demokratin. Det handlar om att se världen ur ett rättviseperspektiv och om att på olika sätt verka för och engagera oss i, som Richard Rorty säger, "the struggle against avoidable human misery".[28] Om historien ses på detta sätt kommer den förvisso aldrig att ta slut.

\section{(C) $\underline{\text { Roddy Nilsson }}$}

[1] Francis Fukuyama, "The End of History", National Interest 16, Summer 1989, s 3-18. [2] Francis Fukuyama, The End of History and the Last Man, New York 1992. Se även Francis Fukuyama, "On the Possibility of Writing a Universal History", i Arthur M Melzer, Jerry Weinberger \& M Richard Zinman (eds), History and the Idea of Progress, Ithaca and London 1995.

[3] Fukuyama har senare utvecklat sina teser och bland annat diskuterat betydelsen av tillit och sociala dygder inom ekonomin. Se Francis Fukuyama, Trust. The Social Virtues and the Creation of Prosperity, London and New York 1995.

[4] Francis Fukuyama, Historiens slut och den sista människan, Stockholm 1992.

[5] Se t ex diskussioner och inlägg i Gordon Marsden (ed), After the End of History, 
London 1992; Howard Williams, David Sullivan \& Gwynn Matthews, Francis Fukuyama and the End of History, Cardiff 1997. Längre svenska recensioner och reflektioner med anledning av Fukuyamas arbete är Anders Stephanson, "Om Fukuyama och historiens slut", Zenit 3-4 1992, s 90-97; Michael Azar, "Den nya världsordningen och Historiens slut", Häften för kritiska studier 2-3, 1994, s 137-148. Särskilt i den senare recensionen visas övertygande på de svagheter som finns inbyggda i Fukuyamas tes.

[6] I sina första versioner återfinns "Historiens slut" naturligtvis i de teologiska världsbilder som vuxit fram ur de monoteistiska religionerna.

[7] Oswald Spengler, Västerlandets undergång. Konturer till en morfologi om världshistorien. Band I och II, Stockholm 1996 (1918 respektive 1922); Arnold Toynbee, Kulturernas historia, Stockholm 1950.

[8] Herbert Butterfield, The Whig Interpretation of History, New York and London 1965 (1931).

[9] Daniel Bell, The end of Ideology: On the Exhaustion of Political Ideas in the Fifties, Glencoe 1960.

[10] Herbert Tingsten, Från idéer till idyll - Den lyckliga demokratin, Stockholm 1966; Strid kring idyllen, Stockholm 1966. För en diskusson se Johan Lundborg, Ideologiernas och religionens död. En analys av Herbert Tingstens ideologi- och religionskritik, Nora 1991.

[11] Herbert Marcuse, One-Dimensional Man, Studies in the Ideology of Advanced Industrial Society, London 1991 (1964).

[12] I min diskussion av Hegel följer jag fr a Williams, Sullivan \& Matthews, Francis Fukuyama, s 24-49 och Terry Pinkard, "Hegel on History, Self-Determination, and the Absolute", i Melzer et el, History, s 30-60.

[13] Francis Fukuyama, "Reply to my Critics", National Interest 18, Winter 1989/90, s 2128.

[14] Det är ur denna synvinkel minst sagt ironiskt att samtidigt som Fukuyama satt i USA och skrev sin bok var detta lands krigsmakt upptagna med att övertyga Saddam Husseins Irak om att historien var slut.

[15] Jean-Francois Lyotard, The Postmodern Condition: A Report on Knowledge, Manchester 1986, s xxiv. Lyotards skrift utkom på franska 1979 och i och första engelsk upplaga 1984. Det är intressant att Fukuyama nästan helt undviker att diskutera den postmoderna utmaningen.

[16] Se t ex Zygmunt Bauman, Legislators and Interpreters. On Modernity, Postmodernity, and Intellectuals, Cambridge 1987; Agnes Heller \& Ferenc Feher, The Postmodern Political Condition, Cambridge 1988; David Harvey, The Conditions of Postmodernity, Cambridge and Oxford 1989; Steven Best \& Douglas Kellner, Postmodern Theory: Critical Interrogations, London 1991; Keith Jenkins, Rethinking History, London 1991; Pauline Marie Rosenau, Post-Modernism and the Social Sciences. Insights, Inroads and Intrusions, Princeton 1992; Barry Smart, Modern Conditions, Postmodern Controversies, London 1992; Barry Smart, Postmodernity, London and New York 1993.

[17] Keith Jenkins, Why History. Ethics and Postmodernity, London and New York 1999, s 85

[18] Jenkins, Why History, s 77.

[19] Det skulle föra alltför långt att här mera ingående diskutera Whites författarskap. Whites grundtankar finns framlagda redan i Metahistory, Baltimore 1973 och har sedan utvecklats i Tropics of Discourse, Baltimore 1979 och Content and Form, Baltimore 1987. Se också t ex Keith Jenkins, On What is History? From Carr and Elton to Rorty and White, London 1995 samt Jenkins, Why History, s 115-132.

[20] Se t ex Isaiah Berlin, Är historien ödesbestämd?, Stockholm 1956; Ramin

Jahanbegloo, Conversations with Isaiah Berlin. Recollections of an Historian of Ideas, London 1992

[21] Jahanbegloo, Conversations, s 44, $142 \mathrm{ff}$.

[22] Fukuyama, Historiens slut, s 301ff.

[23] Fukuyama, Historiens slut, s 312ff.

[24] Fukuyama, "On the Possibility", s 29 (kurs i org).

[25] Fukuyama, Historiens slut, s 322f. 
[26] Skulle någon utopi i dag vara i antågande kanske det som ligger närmast är de budskap som framför av IT-samhällets mest hängivna förespråkare basunerar ut. [27] Tidigare gällde detta framför allt nationalstatens och andra nationella institutioners berättigande.

[28] Richard Rorty, "The End of Leninism and History as Comic Frame", i Melzer et el, History, s 212. Se också Rorty, Kontingens, ironi och solidaritet, Lund 1987; Rorty, Philosophy and social hope, London 1999. Även om Rorty på sätt vis är både romantiker och utvecklingsoptimist - och dessutom har en för en icke-amerikan naiv syn på denna nations förflutna - är han en utomordentligt spännande och inspirerande tänkare. 